\title{
炭酸ガスレーザーによる $\mathrm{SiC}$ 超微粒子の合成
}

\author{
鈴木正昭・中田善徳・奥谷＼cjkstart猛・加藤昭夫* \\ ( * 北海道工業開発試験所, 004 札幌市豊平区月寒東 2 条 17 丁目 2-1 $)$
}

\section{Preparation of SiC Ultrafine Particles by Using $\mathrm{CO}_{2}$ Laser}

\author{
Masaaki SUZUKI, Yoshinori NAKATA, Takeshi OKUTANI and Akio KATO* \\ $\left(\begin{array}{l}\text { Government Industrial Development Laboratory, Hokkaido, } \\ \text { 2-17-2-1, Tsukisamu-Higashi, Toyohira-ku, Sapporo-shi } 004 \\ \text { * Department of Applied Chemistry, Faculty of Engineering, Kyushu University, } \\ \text { 6-10-1, Hakozaki, Higashi-ku, Fukuoka-shi } 812\end{array}\right)$
}

Preparation of $\mathrm{SiC}$ ultrafine particles from $\mathrm{SiH}_{2} \mathrm{Cl}_{2}-\mathrm{C}_{2} \mathrm{H}_{4}$ mixtures by using $\mathrm{CO}_{2}$ laser was investigated. Powders with specific surface areas of 8 to $150 \mathrm{~m}^{2} / \mathrm{g}$, were obtained by irradiating $\mathrm{CO}_{2}$ laser beam to $\mathrm{SiH}_{2} \mathrm{Cl}_{2}-\mathrm{C}_{2} \mathrm{H}_{4}$ gas mixture at atmospheric pressure. The power density of laser beam was $3.66 \mathrm{~kW} / \mathrm{cm}^{2}$ and wave length was 10.6 $\mu \mathrm{m}$. XRD of the products showed that $\mathrm{Si}, \beta$-SiC and free carbon were produced and that the composition of powders depended on the $\mathrm{C}_{2} \mathrm{H}_{4} / \mathrm{SiH}_{2} \mathrm{Cl}_{2}$ ratio. Reaction temperature changed with the power density of laser beam and $\mathrm{C}_{2} \mathrm{H}_{4} / \mathrm{SiH}_{2} \mathrm{Cl}_{2}$ ratio. Hysteresis was observed between reaction temperature and power density of laser beam.

[Received March 27, 1989; Accepted June 23, 1989]

Key-words : $\mathrm{CO}_{2}$ laser, $\mathrm{SiC}$ powder, Ultrafine particle, $\mathrm{SiH}_{2} \mathrm{Cl}_{2}, \mathrm{C}_{2} \mathrm{H}_{4}$

\section{1. はじめに}

$\mathrm{SiC}, \mathrm{Si}_{3} \mathrm{~N}_{4}$ などのセラミックス超微粒子は焼結原料 として注目されている.これらのセラミックス超微粒子 を合成する比較的新しい方法として炭酸ガスレーザーを 使用する方法がある，炭酸ガスレーザーによる $\mathrm{SiC，}$ $\mathrm{Si}_{3} \mathrm{~N}_{4}$ などのセラミックス超微粒子の合成はいくつか報 告1) 5) されているが, 大部分の実験は原料ガスとして $\mathrm{SiH}_{4}$ が使われ，また減圧下で反応が行われている. $\mathrm{SiH}_{4}$ は炭酸ガスレーザー光をよく吸収し, $\mathrm{H}$ 以外の元 素を含まず高純度の超微粒子が得られる利点があるが, 化学的に不安定で取り扱いに注意を要し, しかも大変高 価である. $\mathrm{Si}$ 源として $\mathrm{SiH}_{4}$ 以外のガスを利用し, 反応 を大気圧下で行うことができればより経済的なプロセス が期待できる.

Bauer ら゙) $\mathrm{SiH}_{4}$ よりも取り扱いが容易な $\mathrm{SiH}_{2} \mathrm{Cl}_{2}$, $\mathrm{SiCl}_{4}$ に注目し, 大気圧下で $\mathrm{Si}, \mathrm{Si}_{3} \mathrm{~N}_{4}$ 超微粒子の合成 の検討をしているが，著者らは大気圧下での $\mathrm{SiH}_{2} \mathrm{Cl}_{2}$ か らの $\mathrm{SiC}$ 超微粒子の生成条件について検討した.

\section{2. 実 験}

図 1 に炭酸ガスレーザー反応装置の概略図を示した。 最初に反応容器内を真空に引いた後 Ar ガスで置換し た. 次に $\mathrm{SiH}_{2} \mathrm{Cl}_{2}$ と $\mathrm{C}_{2} \mathrm{H}_{4}$ の混合ガスを内径約 $1 \mathrm{~mm}$ の ステンレス管より噴出させ，それに直角にレーザー光を 照射して反応を起こさせた．約 $10 \mathrm{~mm}$ のビーム径を持 つレーザー光をレンズによって集光させた．反応部での
ビーム径は約 $2 \mathrm{~mm}$ であった.レーザー光の波長は $10.6 \mu \mathrm{m}$ を使用した，反応炎の温度を測定範囲が $1000^{\circ}$ $\sim 2800^{\circ} \mathrm{C}$ のパイロスコープで測定した. 生成した粉体 には強い塩酸臭が認められたため $\mathrm{N}_{2}$ 気流中約 $100^{\circ} \mathrm{C} て ゙$ 2 時間以上, 塩酸臭が認められなくなるまで乾燥した。 生成粉体の分析は X線回折 (XRD), BET 1 点法によ る比表面積測定, 電量測定法による全 $\mathrm{C}$ 量測定を行い, また透過型電子顕微鏡（TEM）により粒子の形態観察 を行った.

\section{3. 結果と考察}

反応ガスである $\mathrm{SiH}_{2} \mathrm{Cl}_{2}$ と $\mathrm{C}_{2} \mathrm{H}_{4}$ レーザー光吸収につ いて調べた. 図 1 に示した反応装置で $100 \mathrm{~W}$ のレーザー 光を反応ガスに照射したときの吸収量を反応ガス流量を 変えて測定した結果を図 2 に示した.レーザー光の波長 は $10.6 \mu \mathrm{m}$ である. $\mathrm{SiH}_{2} \mathrm{Cl}_{2}, \mathrm{C}_{2} \mathrm{H}_{4}$ ともに流量が大き くなると吸収量が増加した.これはレーザー光吸収の過 程が非常に早い反応であるために流量を大きくすると単 位時間当たりにレーザービーム中を通過する反応ガス量 が多くなり全体として吸収量も増加するためと考えられ る. また吸収の程度は $\mathrm{SiH}_{2} \mathrm{Cl}_{2}, \mathrm{C}_{2} \mathrm{H}_{4}$ ともに同じ程度 であった。

表 1 に粉体の合成条件と反応炎温度, 比表面積, XRD の結果を示した．実験はレーザーパワー密度を一 定 $\left(3.66 \mathrm{~kW} / \mathrm{cm}^{2}\right)$ として行った. $\mathrm{SiH}_{2} \mathrm{Cl}_{2}$ 流量が 10 $\mathrm{SCCM}$ のとき, 反応炎温度は $\mathrm{C}_{2} \mathrm{H}_{4} / \mathrm{SiH}_{2} \mathrm{Cl}_{2}$ 流量比が 


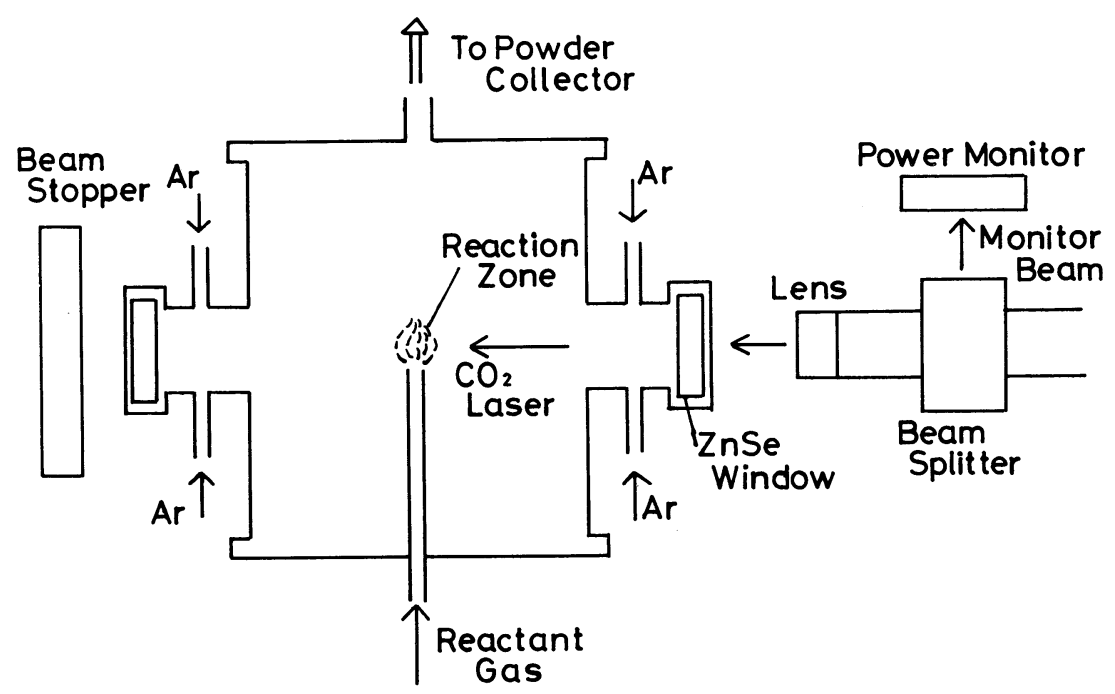

Fig. 1. Schematic diagram of $\mathrm{CO}_{2}$ laser reactor.

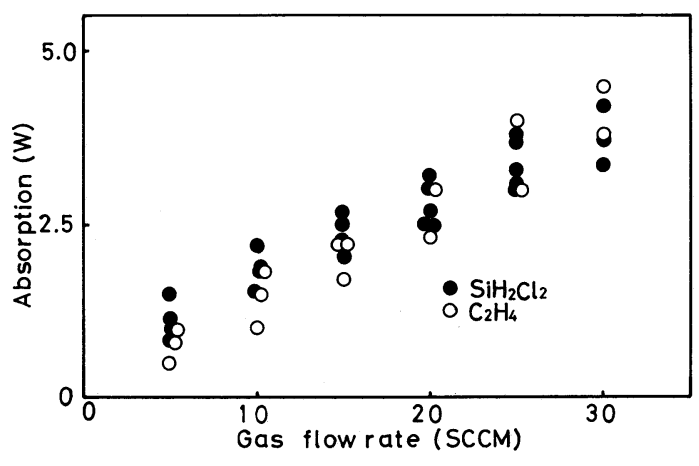

Fig. 2. Absorption amount of laser beam by reactant gases as a function of reactant gas flow rate at irradiation of $100 \mathrm{~W}$ laser beam.

SCCM $=$ Standard Cubic Centimeters per Minute.

Table 1. $\mathrm{SiC}$ powders prepared by $\mathrm{CO}_{2}$ laser. Sample $\mathrm{SiH}_{2} \mathrm{Cl}_{2} \mathrm{C}_{2} \mathrm{H}_{4}$ Reaction Specific

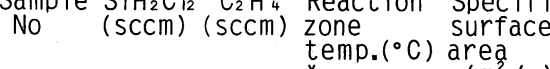

$\begin{array}{rrrcrl}1 & 4 & 15 & --- & 57.4 & \text { C, SiC } \\ 2 & 10 & 0 & <1000 & 14.1 & \text { SiC, Si } \\ 3 & 10 & 3 & <1000 & 44.9 & \text { SiC, Si } \\ 4 & 10 & 5 & >2800 & 153.3 & \text { SiC, C } \\ 5 & 10 & 8 & >2800 & 111.8 & \text { SiC, C } \\ 6 & 10 & 10 & >2800 & 78.1 & \text { C, SiC } \\ 7 & 10 & 13 & >2800 & 67.0 & " \\ 8 & 10 & 15 & >2800 & 72.9 & \text { " } \\ 9 & 20 & 0 & >1000 & 8.6 & \text { Si } \\ 10 & 20 & 5 & 2550-2660 & 104.9 & \text { SiC } \\ 11 & 20 & 10 & 2300-2420 & 79.8 & " 1 \\ 12 & 20 & 12 & >2800 & 61.9 & \text { SiC, C } \\ 13 & 20 & 15 & >2800 & 88.1 & \text { SiC } \\ 14 & 30 & 15 & 1840-1920 & 86.1 & \text { SiC }\end{array}$

*Laser power density $=3.66 \mathrm{kw} / \mathrm{cm}^{2}$

小さいときは $1000^{\circ} \mathrm{C}$ 以下であるが, $\mathrm{C}_{2} \mathrm{H}_{4} / \mathrm{SiH}_{2} \mathrm{Cl}_{2}$ 流 量比が 0.5 以上では急激に $2800^{\circ} \mathrm{C}$ 以上の高い温度を示 した. $\mathrm{SiH}_{2} \mathrm{Cl}_{2}$ 流量が $20 \mathrm{SCCM}$ (Standard Cubic
Centimeter per Minute) の場合も同様の傾向が認めら れた. XRD の結果, 生成物は $\mathrm{SiH}_{2} \mathrm{Cl}_{2}$ のみで製造した ときには $\mathrm{Si}$ が, $\mathrm{C}_{2} \mathrm{H}_{4} / \mathrm{SiH}_{2} \mathrm{Cl}_{2}$ 流量比が小さいときには $\mathrm{SiC}$ と $\mathrm{Si}$ が, $\mathrm{C}_{2} \mathrm{H}_{4} / \mathrm{SiH}_{2} \mathrm{Cl}_{2}$ 流量比が 0.3 程度より大き くなると $\mathrm{SiC}$ のみより , 更に $\mathrm{C}_{2} \mathrm{H}_{4}$ 量が増加すると $\mathrm{SiC}$ のほかにCが生成していることがわかった. SiC は $\beta$-SiC が主成分で一部 $\alpha$-SiC を含むことがわかった. またこれらの粉体中の $\mathrm{Cl}$ 量を原子吸光法による $\mathrm{Ag}$ の 間接定量法で求めた結果, Sample 10 で $0.23 \mathrm{wt} \%$, 同 11 で $0.26 \mathrm{wt} \%$, 同 13 で $0.24 \mathrm{wt} \%$ であり, 不純物と しての $\mathrm{Cl}$ も少なく粉体の純度も良いと考えられる.

図 3 に $\mathrm{C}_{2} \mathrm{H}_{4} / \mathrm{SiH}_{2} \mathrm{Cl}_{2}$ 流量比亡粉体中の全 $\mathrm{C}$ 量の関係 を示した. 全 $\mathrm{C}$ 量は $\mathrm{C}_{2} \mathrm{H}_{4} / \mathrm{SiH}_{2} \mathrm{Cl}_{2}$ 流量比とともに直線 的に変化しており, $\mathrm{C}_{2} \mathrm{H}_{4} / \mathrm{SiH}_{2} \mathrm{Cl}_{2}$ 流量比を変えること により微粉体の組成を制御できることが分かった.

図 4 にこれらの粒子の TEM 写真を示した. $\mathrm{SiH}_{2} \mathrm{Cl}_{2}$ のみの場合 $(\mathrm{A}), 0.1 \sim 0.7 \mu \mathrm{m}$ の大きくて丸い粒子とそ れより小さな粒子が凝集した粒子の 2 種類の粒子がみら れた. $\mathrm{C}_{2} \mathrm{H}_{4}$ を加えていくと粒径が小さくなり $\mathrm{C}_{2} \mathrm{H}_{4}=3$ $\operatorname{SCCM}(\mathrm{B})$ では $0.3 \mu \mathrm{m}$ 程度の大きさの強く凝集した 粒子が多くみられ， $\mathrm{C}_{2} \mathrm{H}_{4}=5 \mathrm{SCCM}(\mathrm{C})$ ではまだいく らか凝集しているが $0.04 \sim 0.07 \mu \mathrm{m}$ のほぼ球形の粒子 が多くみられた. また写真左下にみられるような放射状 の突起を持った粒子が所々に観察された. $\mathrm{C}_{2} \mathrm{H}_{4}=13$ $\operatorname{SCCM}(\mathrm{D})$ になると粒径が少し大きくなり凝集もやや 強くなる傾向がみられた. 放射状の突起を持った粒子の 他に薄片状の粒子も所々に観察された。これらの粒子は Cが主成分ではないかと推測されるが，今後詳しい検討 が必要である.

図 5 にレーザーパワーを変えたときの反応炎温度の変 化を示した. 反応ガス流量と混合比を一定にしてレー 


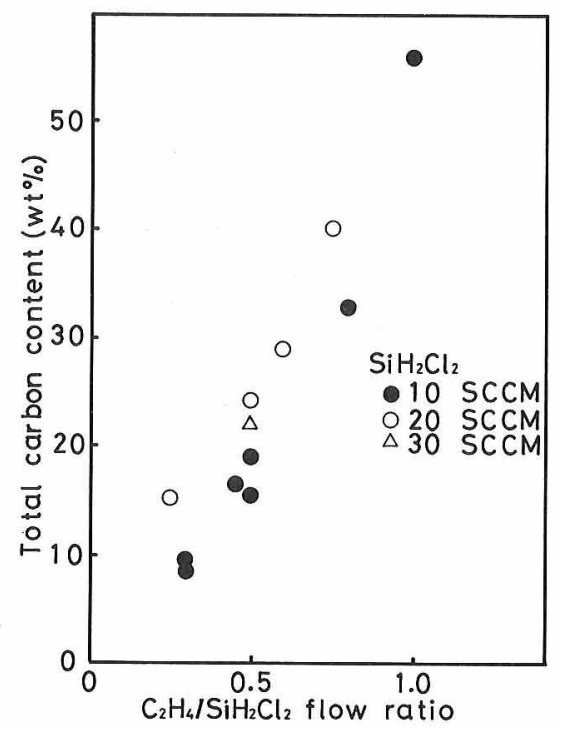

Fig. 3. Effect of $\mathrm{C}_{2} \mathrm{H}_{4} / \mathrm{SiH}_{2} \mathrm{Cl}_{2}$ flow ratio on total carbon content of powder.

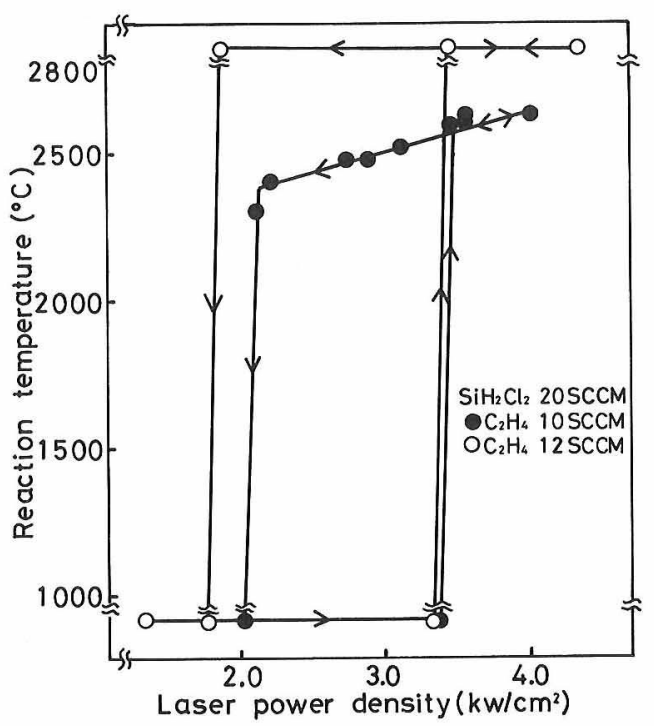

Fig. 5. Reaction temperature change as a function of laser power density.
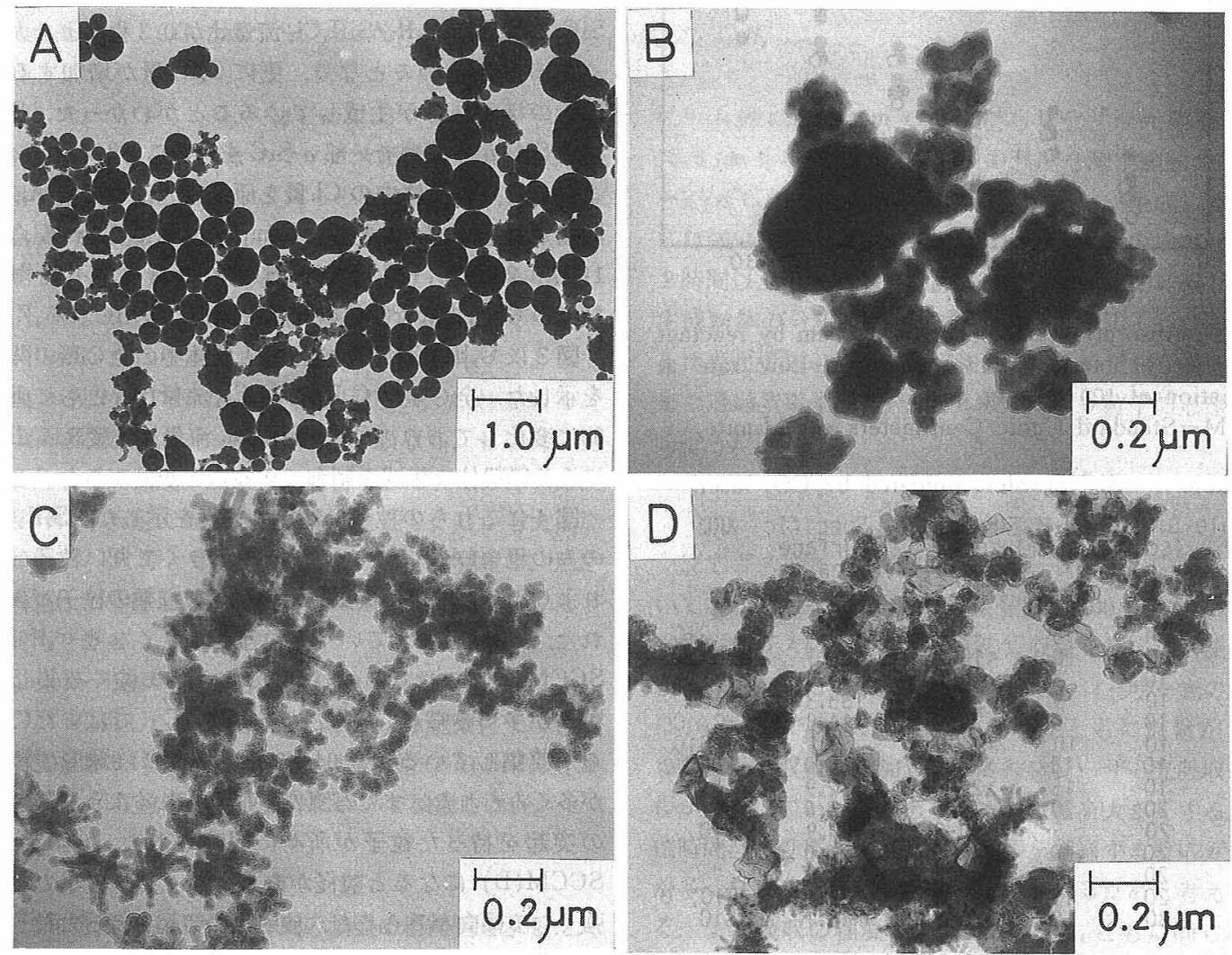

Fig. 4. TEM photographs of particles prepared by $\mathrm{CO}_{2}$ laser.

A : $\mathrm{SiH}_{2} \mathrm{Cl}_{2}=20 \mathrm{SCCM}, \mathrm{C}_{2} \mathrm{H}_{4}=0 \mathrm{SCCM}$

B : $\mathrm{SiH}_{2} \mathrm{Cl}_{2}=10 \mathrm{SCCM}, \mathrm{C}_{2} \mathrm{H}_{4}=3 \mathrm{SCCM}$

C : $\mathrm{SiH}_{2} \mathrm{Cl}_{2}=10 \mathrm{SCCM}, \mathrm{C}_{2} \mathrm{H}_{4}=5 \mathrm{SCCM}$

D : $\mathrm{SiH}_{2} \mathrm{Cl}_{2}=10 \mathrm{SCCM}, \mathrm{C}_{2} \mathrm{H}_{4}=13 \mathrm{SCCM}$ 
ザーパワーを徐々に大きくしていき約 $3.3 \mathrm{~kW} / \mathrm{cm}^{2}$ にな ると反応炎温度は $1000^{\circ} \mathrm{C}$ 以下から $2500^{\circ} \mathrm{C}$ 以上の高温 へ急激に変化した. その後レーザーパワーを小さくして も高温状態を維持し約 $2.0 \mathrm{~kW} / \mathrm{cm}^{2}$ でもとの $1000^{\circ} \mathrm{C}$ 以 下の反応炎温度へ急激に戻った。 $\mathrm{C}_{2} \mathrm{H}_{4}=10 \mathrm{SCCM}$ 上り も $\mathrm{C}_{2} \mathrm{H}_{4}=12 \mathrm{SCCM}$ の方がより低いレーザーパワー密 度まで高温状態を維持することができた．このような履 歴現象は $\mathrm{SiH}_{2} \mathrm{Cl}_{2}$ のみの場合には観測されなかった。 ま たパワー密度, 反応ガス流量を一定として高温状態と低 温状態で作製した粉体を調べたところ，低温状態で作製 された粉体は高温状態のものと比べ C 含量が少なく十分 炭化が進んでいないことがわかった. $\mathrm{C}_{2} \mathrm{H}_{4}$ の分解反応 $1 / 2 \mathrm{C}_{2} \mathrm{H}_{4}(\mathrm{~g}) \rightarrow \mathrm{C}(\mathrm{s})+\mathrm{H}_{2}(\mathrm{~g})$ が $\Delta H=-4.6 \mathrm{kcal} / \mathrm{mol}$ $(1000 \mathrm{~K}), \mathrm{Si}$ の炭化反応 $\mathrm{Si}(\mathrm{s})+\mathrm{C}(\mathrm{s}) \rightarrow \mathrm{SiC}(\mathrm{s})$ が $\Delta H=-17 \mathrm{kcal} / \mathrm{mol}(1000 \mathrm{~K})$ の発熱反応であること から，これらの反応が低温状態から高温状態への遷移に
寄与しているのではないかと考えられる， $\mathrm{SiC}$ 生成の 反応機構については, レーザー照射による $\mathrm{SiH}_{2} \mathrm{Cl}_{2}$ 不均 化反応の可能性もあり今後詳しい検討が必要である.

(1988 年 9 月 日本セラミックス協会秋季シンポジウム発表)

\section{文献}

1) W. R. Cannon, S. C. Danforth, J.H. Flint, J.S. Hag gerty and R. A. Marra, J. Am. Ceram. Soc., 65, 324-30 (1982).

2) Y. Suyama, R. M. Marra, J.S. Haggerty and H. K. Bowen, Am. Ceram. Soc. Bull., 64, 1356-59 (1985).

3）澤野清志, J.S. Haggerty, H. K. Bowen, 窯協, 95, 64-69 (1987).

4) Y. Kizaki, T. Kandori and Y. Fujitani, Jpn. J. Appl. Phys., 24, 800-05 (1985).

5) R. A. Bauer, R. Smulders, E. R. Geus, P. J. van der Put, J. G. M. Becht and J. Schoonman, Ceram. Eng. Sci. Proc., 9, 949-56 (1988). 